\title{
Production of Red Pigment from Fungal Isolate DMMS-1
}

\author{
Manan Sankhyayan ${ }^{1}$, Abhishek Walia ${ }^{1,2}$ and Chayanika Putatunda ${ }^{1 *}$ \\ ${ }^{1}$ Department of Microbiology, DAV University, Village Sarmastpur, Jalandhar, Pathankot \\ National Highway, NH 44, Jalandhar, Punjab 144012, India \\ ${ }^{2}$ Department of Microbiology, CSK Himachal Pradesh Agriculture University Palampur, \\ Himachal Pradesh 176062, India \\ *Corresponding author
}

\begin{tabular}{|c|c|}
\hline & A B S T R A C T \\
\hline Keywords & \multirow{4}{*}{$\begin{array}{l}\text { Pigments play a very significant role in all aspects of life. They find application in a } \\
\text { variety of industries like food industries, textile industries, pharmaceutical industries etc. } \\
\text { One of the major reasons behind the increasing market interest for microbial pigments is } \\
\text { their eco-friendly nature and their compatibility with the living. Besides this, they also } \\
\text { reported to impart many additional benefits due to their anti-bacterial, anti-oxidant, anti- } \\
\text { malarial and anti-biotic properties etc. In the present investigation, a fungal isolate } \\
\text { DMMS-1, isolated from the soil sample, was seen to produce red colored pigment. The } \\
\text { conditions for higher pigment production were optimized. It was observed that the } \\
\text { temperature of } 37^{\circ} \mathrm{C} \text {, inoculum size of } 3 \text { plugs }(5 \mathrm{~mm} \text { diameter), malt extract as carbon } \\
\text { source, pH of } 7.5 \text { and the shaking incubation }(110 \mathrm{rpm}) \text { resulted in enhancement of } \\
\text { pigment production. }\end{array}$} \\
\hline $\begin{array}{l}\text { Microbial pigments, } \\
\text { Fungal pigment, } \\
\text { Soil fungi, Red }\end{array}$ & \\
\hline Article Info & \\
\hline $\begin{array}{l}\text { Accepted: } \\
\text { 20 March } 2019 \\
\text { Available Online: } \\
10 \text { April } 2019\end{array}$ & \\
\hline
\end{tabular}

\section{Introduction}

Colors have a very noteworthy role in one's life; Colours have been used for therapeutic tenacity since ages. They play a significant role in setting up one's mood, emotions, feelings and state of mind. Colour is even a medium of communication. Since colours means so much in one's life, they have a wide variety of applications; they are used in food industries as colorants, in textile industries as dyes, as antioxidants in pharmaceuticals and cosmetic industries etc. (Kumar et al., 2015). Man puts color on everything he creates in order to make it more eye catching. One wants to be surrounded by a colorful environment. The market is full of industrialized goods, the increased market demand of color has put a lot of pressure on the industries to synthesize high amount of color in order to satisfy its insatiable demand, to do so the industries have been producing the color by the chemical means. Most of the chemical used are of very poor quality. There have been cases reported the chemical dyes causing dermatitis, respiratory disorders, irritation in the upper respiratory tract and mucosal membrane (Bansal and Yadav 2016; 
Ozkurt et al., 2012).Some researchers have been successful in proving the carcinogenic nature of these chemicals (Azo dyes to be specific) (Khandare and Govindwar 2015).Though one wants to be surrounded by an environment which is colourful but healthy as well. Due to their compatibility with the livings and the environment the natural pigments are gaining interest as an alternative to these chemical dyes globally. In natural pigments microbial pigments are the most efficient to use as the time and capital investment in case of plant origin pigment is very high and the efficiency is very poor, where as in case of animal origin pigments it's not only the cost and poor yield but the ethical issues too. Besides this nature consists a plethora of microbes producing pigment which not only imparts color but many additional advantages like anti-proliferative, anti-biotic etc. At one side where the chemical dyes have potential to cause cancer on the other the microbial pigments possess anti- cancerous traits (Heer and Sharma, 2017). Here we have worked on the isolation and purification of a fungal isolate DMMS-1 and the standardization of the conditions for maximum pigment production.

\section{Materials and Methods}

\section{Isolation}

A soil sample from the agricultural fields of DAV University campus was taken diluted and was spread on N.A plates incubated at $37^{\circ} \mathrm{C}$. A mixed culture was obtained in which the fungal isolate DMMS-1 was found to secrete a red coloured pigment in its periphery.

\section{Purification}

The fungal isolate was purified on the potato dextrose agar (PDA) and malt extract agar (MEA) medium by streaking. MEA was found to favour the pigment production so MEA was selected for the future use.

\section{Preparation of seed culture}

For preparation of seed culture an MEA plate streaked with fungal isolate was incubated at $37^{\circ} \mathrm{C}$ for 3 days. The $\mathrm{pH}$ of the medium was adjusted to be 5.5. After 3 days a full plate growth was obtained and that plate served as the seed culture for the liquid culture.

\section{Production of pigment under liquid culture condition}

Plugs from the 3-day old seed culture were cut with the help of a borer $5 \mathrm{~mm}$ in diameter. The plugs were then inoculated to the MEA broth and the flasks with inoculated MEA broth were incubated at $37^{\circ} \mathrm{C}$ for an incubation period of 10 days. After 10 days of incubation a significant amount of pigment was obtained in the flasks. Since the pigment produced by the fungal isolate DMMS-1 is water soluble in nature, it was directly obtained in the broth.

\section{Pigment Filtration and analysis}

The layer of the fungal biomass formed at the top of the broth containing pigment was filtered using normal filter paper. The absorbance maxima for the obtained pigment were found to be $535 \mathrm{~nm}$ and hence the pigment obtained was analysed spectrophotometrically at a wavelength of 535 $\mathrm{nm}$ for further analysis. Un-inoculated MEA broth was used as the control/blank.

\section{Standardization of conditions}

The effect of conditions like inoculum size, $\mathrm{pH}$ of the medium, carbon source, nitrogen source, temperature, shaking vs non-shaking conditions were assessed by changing one parameter at a time. 


\section{Results and Discussion}

A soil sample from the agricultural fields of DAV University campus was taken diluted and was spread on N.A plates incubated at $37^{\circ} \mathrm{C}$. A mixed culture was obtained in which the fungal isolate (later named as DMMS-1) was found to secrete a red coloured pigment in its periphery. The fungal isolate was purified on the potato dextrose agar (PDA) and malt extract agar (MEA) medium by streaking. MEA was found to favour the pigment production so MEA was selected for the future use as a pronounced pigment secretion was observed (Fig. 1). The isolate was further cultivated under liquid culture conditions and the $\lambda$ max of pigment secreted in the broth was determined spectrophotometrically (Fig. 2). The absorbance maxima for the pigment was found to be $535 \mathrm{~nm}$ and hence the pigment obtained was analysed spectrophotometrically at a wavelength of $535 \mathrm{~nm}$ for further analysis.

The effects of various cultural parameters on the pigment production by the fungal isolate were assessed. Flasks containing MEA broth were inoculated with different number of plugs $(5 \mathrm{~mm}$ in diameter) of seed culture. After the incubation of 10 days flasks with the inoculum size of 3 plugs was found to have synthesized the maximum pigment as compared to the flasks with inoculum size of 1, 2 and 4 plugs (Fig. 3). Similar results were reported by Bhat and Marar (2015) where increasing inoculum percentage first lead to increase and then constant decrease in the pigment production by Salinicoccus sp M KJ99797. Also, Studies conducted by Babitha et al., (2007) also suggested that the increase in inoculum size may increase the biomass but decreases the pigment production.

For assessing the impact of $\mathrm{pH}$, flasks containing MEA broth with $\mathrm{pH}$ ranging from
3.5- 8.5 were inoculated with 3 plugs of the seed culture and were incubated for 10 days at $37^{\circ} \mathrm{C}$ resulting in the flask with $\mathrm{pH} 7.5$ yielding the maximum pigment production (Fig. 4). Similar results were also observed by Babitha et al., (2007) and reported the highest pigment yield by Monascus perpureus was at a $\mathrm{pH}$ range of 4.5 to 7.5. Also, HernándezRivera, et al., (2008) found that the $\mathrm{pH}$ at which the highest production of red pigment produced by Monascus cultures was between $7.0-7.5$.

For analyzing the impact of temperature on the pigment production, MEA flasks $(\mathrm{pH} 7.5$ \& 3 plugs) were incubated for 10 days at $28^{\circ} \mathrm{C}, 37^{\circ} \mathrm{C}$ and $45^{\circ} \mathrm{C}$. Maximum yield of pigment was obtained in the flasks kept at $37^{\circ} \mathrm{C}$ whereas almost negligible growth in flasks incubated at $45^{\circ} \mathrm{C}$. An intermediate amount of pigment was obtained in the flasks kept at $25^{\circ} \mathrm{C}$ (Fig. 5). While analyzing pigment produced by Penicillium purpurogenum, Patil et al., (2015) found that the temperature of $27^{\circ} \mathrm{C}$ is the temperature at which the highest pigment production was observed. Ahn et al., (2006) observed that the pigment produced by Monascus cultures at $30^{\circ} \mathrm{C}$ is ten times lesser than the pigment produced by it at $25^{\circ} \mathrm{C}$.

In order to assess the effect of shaking on pigment production of the isolate, two sets of flasks containing MEA ( $\mathrm{pH} 7.5$ ) inoculum size of 3 plugs were incubated at $37^{\circ} \mathrm{C}$ for 10 days. Set 1 was kept in the non-shaking incubation whereas set 2 was kept under shaking incubation at $110 \mathrm{rpm}$. It was found that the amount of pigment produced in the flasks kept under shaking condition (110 rpm) was double than that of produced in the nonshaking condition (Fig. 6). Similar results were reported by Usman et al., (2018) where the orange pigment produced by Salinococcus roseus under shaking incubation was approximately three times the pigment 
produced under non-shaking incubation. The nutrients also play a very significant effect on the metabolic activities of all the living organisms, hence the effect of carbon and nitrogen on pigment production was assessed.
Effect of different carbon sources was analysed by replacing the Malt Extract with an equal amount of lactose, fructose and dextrose in the medium/broth.

Fig.1(a) Front view of Petri plate with Fungal isolate DMMS-1 growth, (b) Rear view of the Petri plate with pigment secreted by the fungal isolate
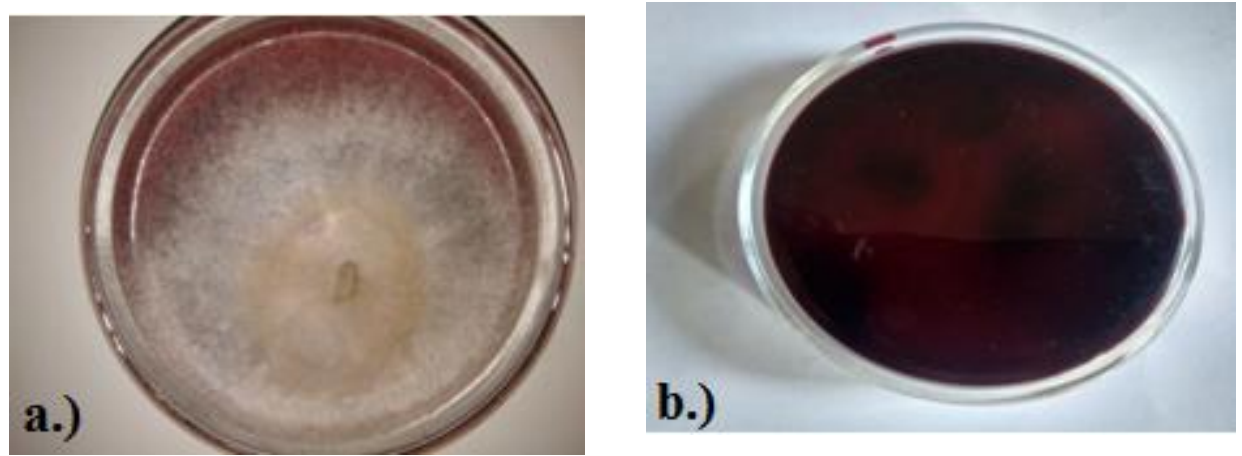

Fig.2 Uninoculated ME Broth used as control (Left) and pigment obtained from the broth inoculated with the fungal isolate DMMS-1 (Right)

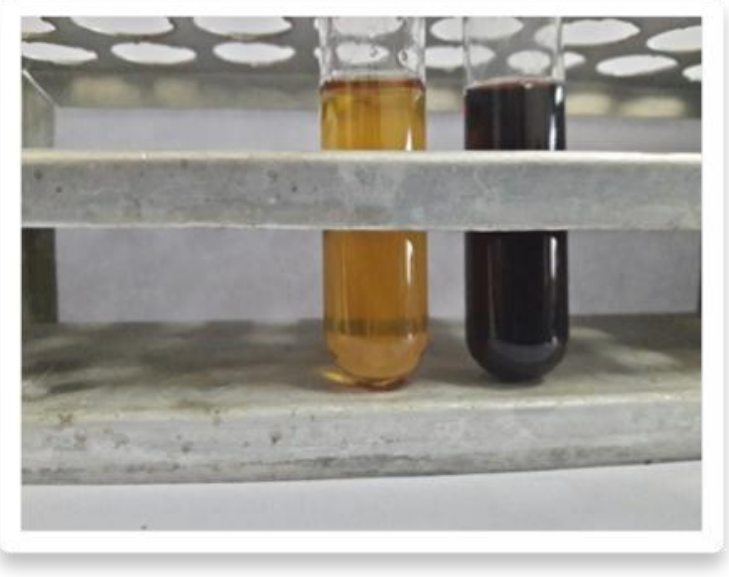

Fig.3 Effect of inoculum size on the pigment production by fungal isolate DMMS-1

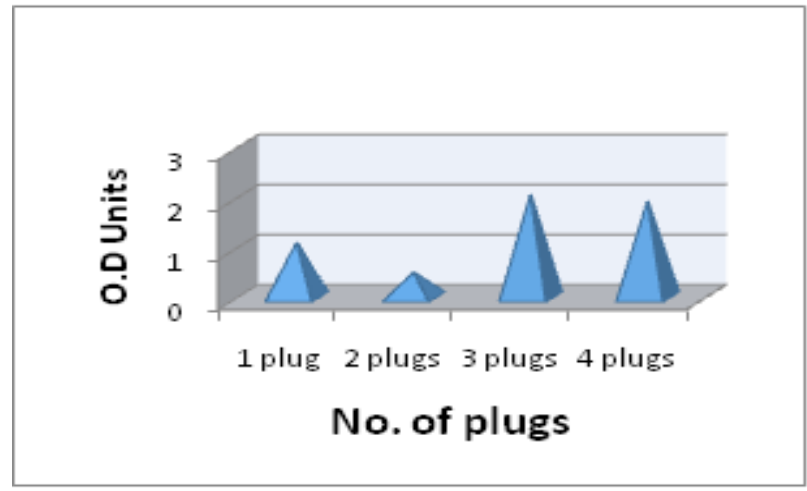


Fig.4 Effect of pH on the pigment production by fungal isolate DMMS-1

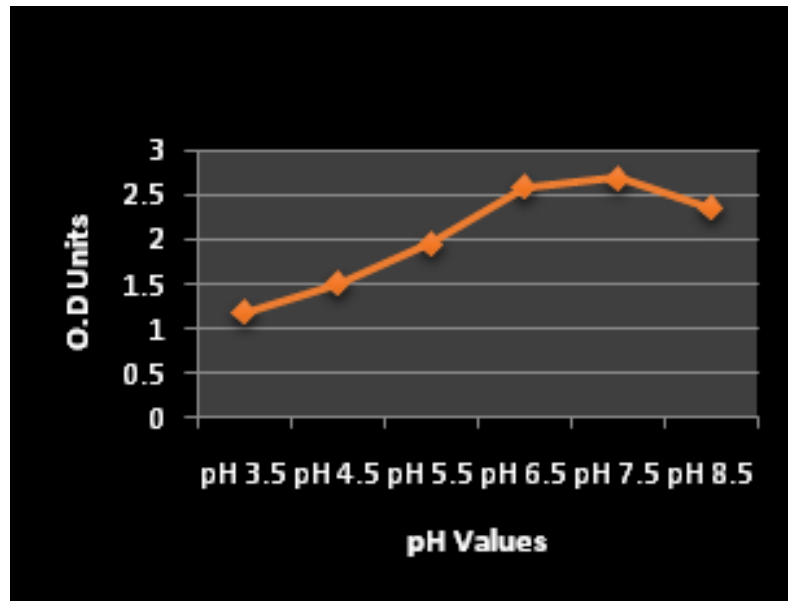

Fig.5 Effect of temperature on the pigment production by fungal isolate DMMS-1

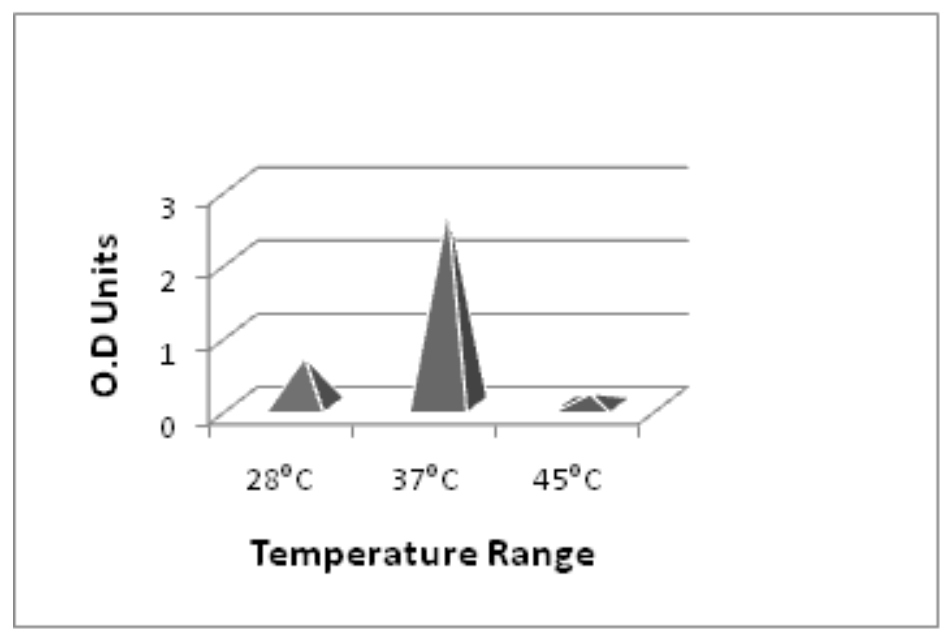

Fig.6 Effect of Shaking/non-shaking condition on the pigment production by fungal isolate DMMS-1

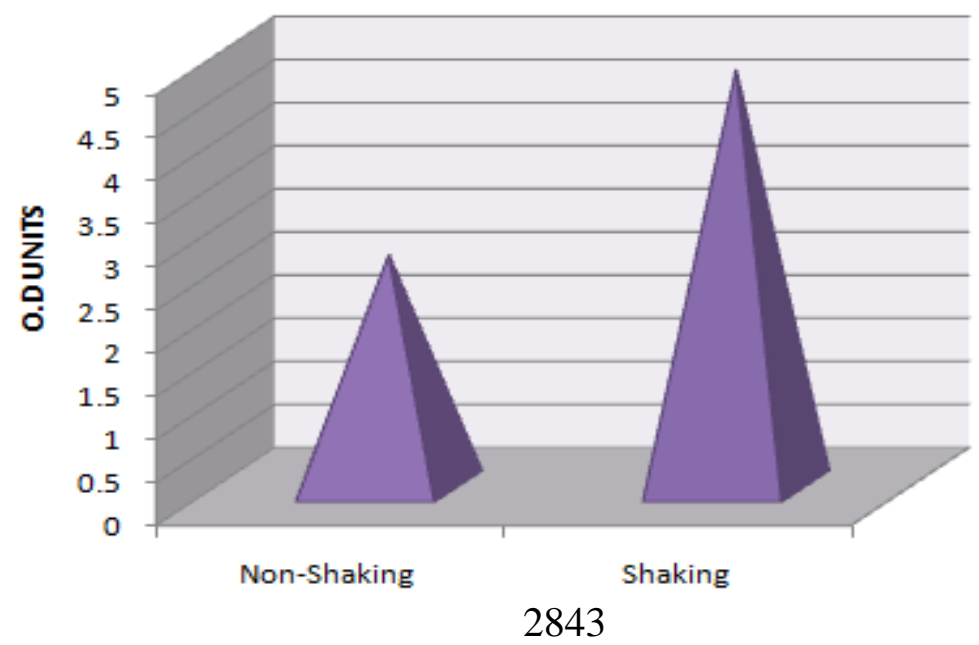


Fig.7 Effect of carbon source on the pigment production by fungal isolate DMMS-1

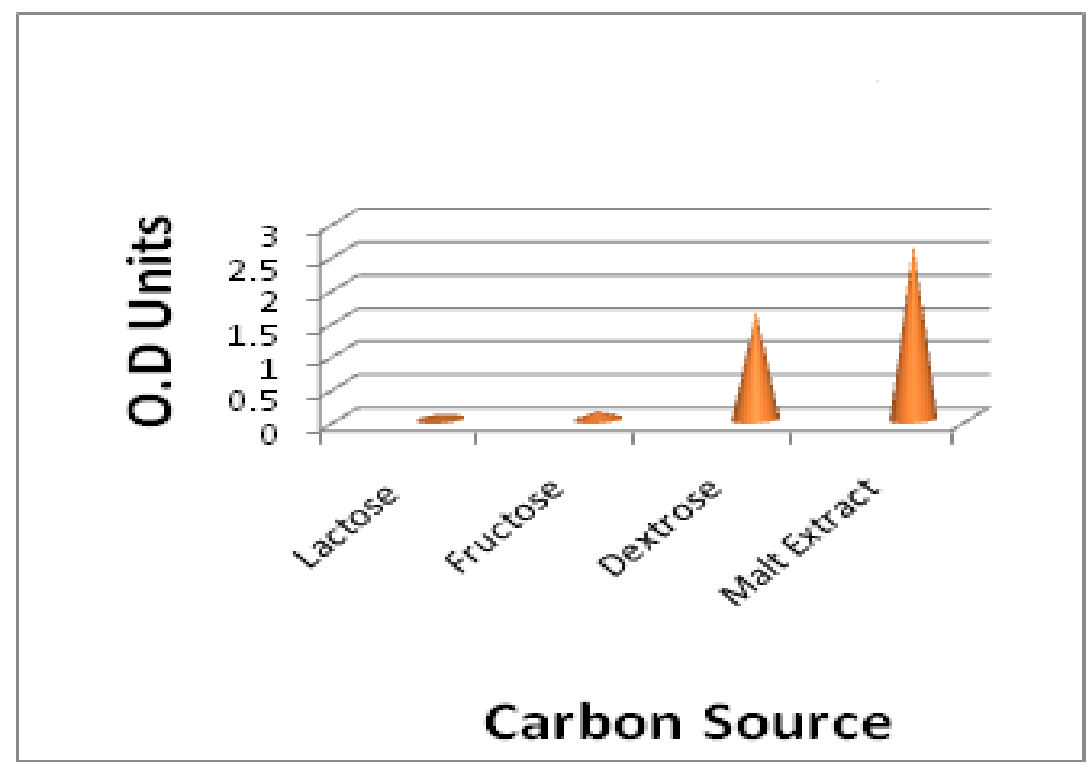

Fig.8 Effect of Nitrogen source on pigment production by fungal isolate DMMS-1

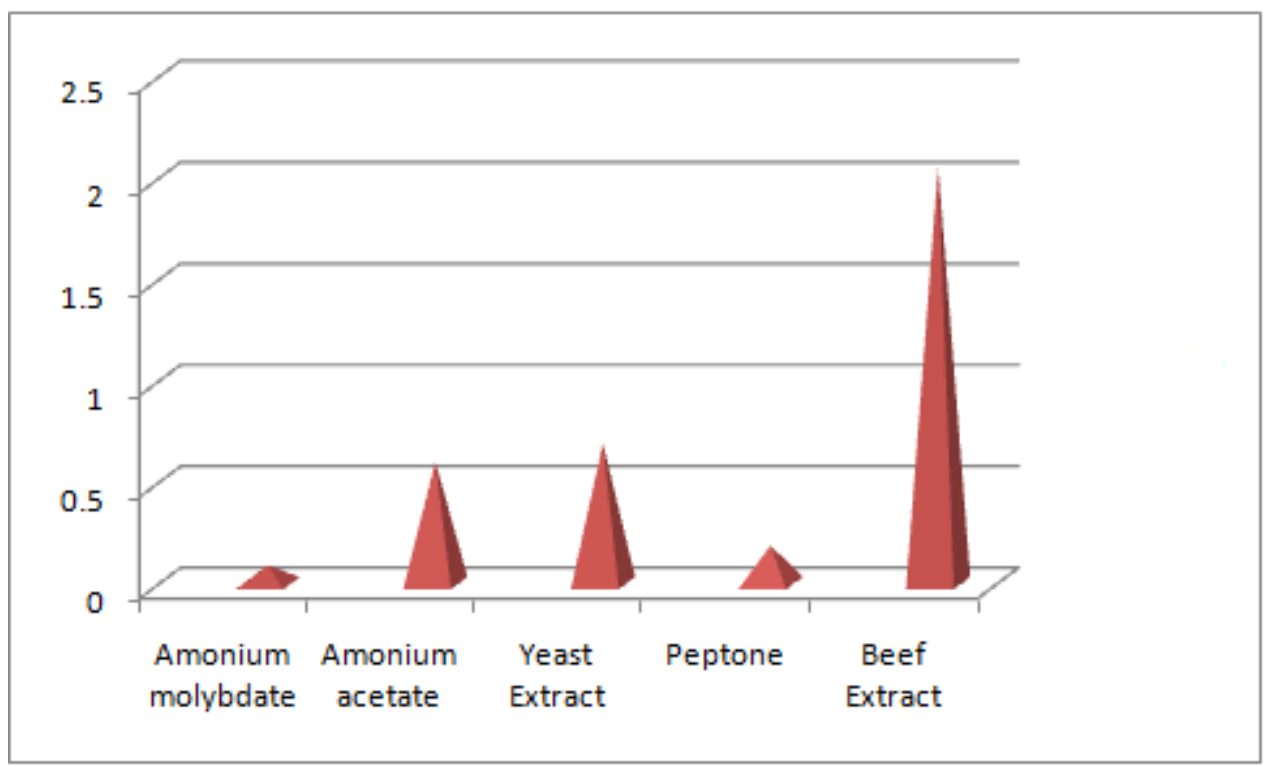

$\mathrm{pH}$ of the media was adjusted to 7.5 and flasks were inoculated with 3 plugs each. The order of increasing pigment production was found to be: Lactose < fructose < dextrose < malt extract. Here malt extract supported the maximum pigment production whereas the pigment production in lactose and fructose were disappointingly low (Fig. 7). Similar results were found by da Costa Souza et al.,
(2016) they found that potato dextrose and Malt extract favoured increased pigment production. Also Subhsree et al., (2011) found fructose as the best suited carbon source for the pigment production from Monascus perpureus. For nitrogen source, flasks containing MEA broth with 3 plugs of seed culture and $\mathrm{pH} 7.5$ were supplemented with different nitrogen sources like 
Ammonium sulphate, Ammonium Molybdate, beef extract, peptone and yeast extract. The supplementation of nitrogen to the medium rather led to the decrease in the pigment production. Out of all maximum pigment was obtained in the flasks containing beef extract but was less than the pigment amount obtained without any nitrogen supplementation (Fig. 8). Chen and John (1993) observed that the Monascus perpureus growth along with the pigment production is affected by the nature of the nitrogen, where peptone and ammonium gave higher growth and pigment production than nitrate. Also Subhsree et al., (2011) reported Yeast Extract as the nitrogen source under which the highest pigment production by Monascus perpureus was achieved.

In conclusion, the present investigation was carried out with the aim of characterization of the fungal isolate DMMS-1, with respect to red pigment production. The isolate shows promising results in the preliminary investigations, since it secreted a red colored pigment into the culture broth. Thus, this pigment could be easily harvested without breaking of the fungal biomass. It was observed that the temperature of $37^{\circ} \mathrm{C}$, inoculum size of 3 plugs ( $5 \mathrm{~mm}$ diameter), malt extract as carbon source, $\mathrm{pH}$ of 7.5 and the shaking incubation (110 rpm) resulted in enhancement of pigment production. So, more research is required to identify the fungus and analyze the characteristics of the red colored pigment in order to ascertain its possible commercial application in various industries.

\section{References}

Ahmad W.A., Ahmad W.Y.W., Zakaria Z.A., and Yusof N.Z. 2012. Introduction. In: Application of Bacterial Pigments as Colorant. Springer Briefs in Molecular Science. Springer, Berlin, Heidelberg. Pp. $25-$
44.

Ahn, J., Jung, J., Hyung., W, Haam, S., and Shin, C. 2006. Enhancement of Monascus pigment production by the culture of Monascus sp. J101 at low temperature. Biotechnol. Prog. 22(1): 338-340.

Babitha, S., Soccol, C.R., and Pandey, A. (2006). Jackfruit Seed - a novel substrate for the production of Monascus pigments through solid-state fermentation. Food Technol. Biotechnol. 44: 465-471.

Bansal, M., and Yadav, R. K. 2016. Occupational health hazards and awareness of occupational safety among workers of textile dyeing industries in Jaipur, India. SGVU Int J Env Sci Tenchnol. 2(2): 30-38.

Bhat, M. R., and Marar, T. 2015. Media optimization, Extraction and partial characterization of an Orange pigment from Salinicoccus sp. MKJ997975.Int. J. Life Sci. Biotech. Pharm. Res. 4(2): 85-89.

Chen, M. H., and Johns, M. R.1993.Effect of $\mathrm{pH}$ and nitrogen source on pigment production by Monascus puropureus. Appl Microbiol Biotechnol. 40(1): 132138.

Corpe, W.A., 1953. Variation in pigmentation and morphology of colonies of Gelatinous Strain of Chromobacterium species from soil. J Bacteriol. 66(4): 470-477.

da Costa Souza., P.N, Grigoletto, T.L.B., de Moraes, L.A.B., Abreu, L.M., Guimaraes, L.H.S., Santos, C., Galvao, L.R., and Cardoso, P.G. 2016. Production and chemical characterization of pigments in filamentous fungi. Microbiol. 162: 1222.

Gomah, N. H., Abdel-Reheam, H.E. F., and Mohamed,T. H. 2017. Production of natural pigment from Monascus Ruber 
by solid state fermentation of broken rice and its application as colorants of some dairy products. J. Food and Dairy Sci., Mansoura Univ. 8(1): 37-43.

Hamano, P. S., and Kilikian, B. B. 2006. Production of red pigments by Monascus ruber in culture media containing corn steep liquor. Braz. J. Chem. Eng. 23(4): 443-449.

Heer, K., and Sharma, S. 2017.Microbial pigments as a natural color: A review. Int J Pharm Sci Res. 8(5): 1913-22.

Khandare, R.V., and Govindwar, S. P. 2015. Phytoremediation of textile dyes and effluents: Current scenario and future prospects. Biotechnol Advs. 33(8): $1697-714$.

Kumar, A., Vishwakarma, H. S., Singh, J., Dwivedi, S., and Kumar, M. 2015.Microbial Pigments: Production and their applications in various industries. IJPCBS. 5(1): 203-212.

Mendez, A., Peref, C., Montanez, J. C., Martinez, G., and Aguilar, C. N. 2011. Red pigment production by Penicillium purpurogenum $\mathrm{GH} 2$ is influenced by $\mathrm{pH}$ and temperature. $\mathrm{J}$ Zhejiang UnivSci B (Biomed \& Biotechnol). 12(12): 961-968.

Ozkurt, S., Kargi, B. A., Kavas, M., Evyapan, F., Kiter, G., and Baser, S. 2012. Respiratory Symptoms and Pulmonary Functions of Workers Employed in Turkish Textile Dyeing Factories. Int. J. Environ. Res. Public Health. 9(4): 10681076.

Parmar, R.S., Singh, C., and Kumar, A. 2017.
Optimization of Cultural Parameters for pigment production from Streptomyces flavofuscus ARITM02, isolated from Rhizosphere soil. Int.J.Curr.Microbiol. App.Sci.6(2): 961-966.

Patil, S.A., Sivanandanan, G., and Thakare, D.B. 2015. Effect of physical and chemical parameters on the production of red exopigment from Penicillium purpurogenum isolated from spoilt onion and study of its anti-microbial activity. Int.J.Curr.Microbiol.App.Sci. 4(7): 599-609.

Sayyed, I., and Majumder, D. R. 2015. Pigment Production from Fungi. Int.J.Curr.Microbiol.App.Sci. 2: $103-$ 109.

Sharma, D., Gupta, C., Aggarwal, S., and Nagpal, N.2012. Pigment Extraction from fungus for textile dyeing. Indian $\mathrm{J}$. Fibre text. Res. 37: 68-73.

Singh, Z., and Chadha, P. 2016. Textile industry and occupational cancer. J Occ Med \& Toxicol. 16:39.

Subashree, R.S., Babu, P.D., Vidyalakshmi, R., and Mohan, V. C. 2011. Effect of carbon and nitrogen sources on stimulation of pigment production by Monascus purpureus on jackfruit seeds. Intl. J. Microbiol. Res. 2(2): 184-187.

Usman, H. M., Farouq, AA., Baki, AS., Abdulkadir, N., and Mustapha, G. 2018. Production and characterization of orange pigment produced by Halophilic bacterium Salinoccocus roseus isolated from Abattoir soil. J Microbiol Exp. 6(6): 238-243.

\section{How to cite this article:}

Manan Sankhyayan, Abhishek Walia and Chayanika Putatunda. 2019. Production of Red Pigment from Fungal Isolate DMMS-1. Int.J.Curr.Microbiol.App.Sci. 8(04): 2839-2846. doi: https://doi.org/10.20546/ijcmas.2019.804.331 